Article

\title{
Synthesis and Characterization of Hydrogenated Diamond-Like Carbon (HDLC) Nanocomposite Films with Metal (Ag, Cu) Nanoparticles
}

\author{
Loukas Koutsokeras *(D), Marios Constantinou, Petros Nikolaou, Georgios Constantinides and \\ Pantelis Kelires \\ Research Unit for Nanostructured Materials Systems (RUNMS), Department of Mechanical Engineering and \\ Materials science and Engineering, Cyprus University of Technology, Limassol 3046, Cyprus \\ * Correspondence: 1.koutsokeras@cut.ac.cy; Tel.: +357-25002151
}

Received: 20 January 2020; Accepted: 7 April 2020; Published: 9 April 2020

\begin{abstract}
In this work, the synthesis and characterization of hydrogenated diamond-like carbon (HDLC) nanocomposite thin films with embedded metallic Ag and Cu nanoparticles (NPs) are studied. These nanocomposite films were deposited using a hybrid technique with independent control over the carbon and metal sources. The metallic nanoparticles were directly deposited from the gas phase, avoiding surface diffusion of metal species on the deposition surface. The structural features, surface topography and optical properties of pure and nanocomposite HDLC films are studied and the effect of metal introduction into the carbon matrix is discussed. The interactions between the carbon ion beam and the NPs are considered and it is demonstrated that the nanocomposite HDLC:metal films, especially for $\mathrm{Cu}$ NPs, can retain the transparency level of the pure HDLC, by limiting the interactions between metal and carbon during deposition.
\end{abstract}

Keywords: hydrogenated diamond like carbon; nanocomposite thin films; silver nanoparticles; copper nanoparticles; cluster beam source

\section{Introduction}

Amorphous carbon $(\mathrm{a}-\mathrm{C})$ and its hydrogenated form $(\mathrm{a}-\mathrm{C}: \mathrm{H})$ have attracted significant attention in the scientific community due to their interesting properties such as chemical inertness, low friction coefficient, wear resistance, optical transparency, and biocompatibility, among others [1-6]. All these properties arise from the complexity and the configurational possibilities of the amorphous network pertinent to $\mathrm{C}-\mathrm{C}$ and $\mathrm{C}-\mathrm{H}$ bonds. The fraction of the $\mathrm{sp}^{3}$ and $\mathrm{sp}^{2}$ sites as well as the hydrogen content are the most influential characteristics of the material that subsequently dictate its properties. Amorphous carbon with high $\mathrm{sp}^{3} / \mathrm{sp}^{2}$ bonds-ratio is called Diamond Like Carbon (DLC) and has properties resembling crystalline diamond [7]. The hydrogenated form of DLC is commonly abbreviated as HDLC and its properties are affected also by the hydrogen content [8,9]; it is a material with many photonic applications $[10,11]$. The deposition of DLC and HDLC films is usually based on some variant of the chemical vapor deposition (CVD) technique, such as capacitively coupled plasma enhanced CVD (PECVD), which is the most commonly used deposition method, electron cyclotron resonance CVD (ECR CVD) and microwave plasma CVD (MPCVD), among others [4,12,13]. Additionally, physical vapor deposition (PVD) methods have been used to deposit DLC and HDLC films, such as magnetron sputtering (MS), high power impulse magnetron sputtering (HiPIMS) [14,15] and pulsed laser deposition (PLD) [16].

The addition of metal nanoparticles in an amorphous carbon matrix (hydrogenated or not) can lead to multifunctional materials with properties such as high catalytic activity [17], enhanced solar 
absorption [18,19] and nanoscratch resistance [20-23], among others. For photonic and plasmonic applications especially, a transparent HDLC matrix is desired in order to support the localized surface plasmon resonance (LSPR) of metallic NPs, such as $\mathrm{Au}, \mathrm{Ag}$ and $\mathrm{Cu}$. The intensity and position of the LSPR peak are affected by the NPs size, distribution, shape, interparticle distance and also by the refractive index of the matrix.

The techniques used to produce HDLC nanocomposites are usually realized by the deposition of metal species by sputtering in a reactive hydrocarbon atmosphere [14,24], or by metal ion implantation and aggregation/growth via post growth annealing [25]. The reactive sputtering approach, which is widely used, deposits nanocomposite thin films with a broad range of metal content that ranges from 0 to $60 \%$ atomic. The size of the NPs is usually in the range of 2 to $25 \mathrm{~nm}$ and their average size is also coupled with the metal content $[26,27]$. Furthermore, the distance between particles is small especially for high metal concentration. Until now the LSPR peak has been observed only for metal contents above 3\% for Ag and 9\% for $\mathrm{Cu}$ NPs in similar HDLC nanocomposites [26-28].

The absence of the LSPR manifestation in lower metal concentrations we believe is due to the reduction of the HDLC transparency. The introduction of metals in the HDLC matrix induces graphitization [21,28-30], which in turn reduces the optical transparency of the films due to $\pi-\pi^{*}$ transition [11] (of the $\mathrm{sp}^{2}$ network). For low metal contents, the concentration of plasmonic NPs is not enough to overcome the loss of transparency. High transparency levels of the HDLC matrix are required for LSPR manifestation at lower metal contents.

In this work, we study the optical properties of HDLC nanocomposites with Ag and $\mathrm{Cu}$ NPs focused on their potential for plasmonic and photonic applications such as antireflective coatings and sensors. A novel CVD/PVD hybrid deposition system is used where matrix and metal nanoparticles are deposited from different sources. The HDLC matrix is deposited by an RF ion beam using a $\mathrm{CH}_{4} / \mathrm{Ar}$ plasma and the NPs by a nanocluster beam source. For comparison we deposited thin films of pure HDLC, plain NPs and a combination of both (nanocomposites) and we discuss the effect of the metals to the transparency of the HDLC matrix and the relative LSPR manifestation. The HDLC matrix features are discussed after the addition of metals by comparing the effect of the $\pi$ - $\pi^{*}$ transition and the plasmon resonance in the optical spectrum.

\section{Materials and Methods}

All samples were deposited on Czochralski-grown commercial silicon (001) and quartz (c-cut) wafers and depositions were carried out in a high vacuum chamber with basic pressure lower than $10^{-5} \mathrm{~Pa}$, pumped down by a turbomolecular and a dry scroll pump. All substrates were ultrasonically cleaned for $10 \mathrm{~min}$ in acetone and methanol baths and dried in nitrogen flow. An ion beam source (RFMAX60, Mantis Deposition Ltd., Thame, UK) with an RF inductively coupled plasma was used to produce the hydrogenated amorphous carbon films. The ion beam source consisted of a quartz cup surrounded by an RF coil and a set of two highly transparent graphite grids located at the exit of the cup. RF power (at $13.56 \mathrm{MHz}$ ) applied to the coil, ionized the gaseous species in the quartz cup and produced an inductively coupled plasma with high ionization degree. The plasma lost electrons at the walls of the quartz cup and obtained a positive plasma potential which was in the order of $40-50 \mathrm{~V}$. Through the inner graphite grid, the plasma potential could be raised to a selected value and this created a voltage drop with the outer grounded grid. This voltage drop extracted and accelerated ions from the plasma to the substrate, forming a beam with narrow kinetic energy distribution of ions. The diameter of the beam was 2 inches with an incident angle of $30^{\circ}$ from the substrate's surface normal.

Metal NPs were deposited directly from gas phase by a NP source (Nanogen50, Mantis Deposition Ltd., Thame, UK). This source was a modified magnetron sputtering with a gas aggregation zone where nucleation and growth of the sputtered species occurred in the gas phase. The NPs were formed inside this aggregation zone where vapors from the sputtering target nucleated and grew due to high argon pressure and gas phase collisions. The NPs exited the aggregation zone through a narrow aperture of $5 \mathrm{~mm}$ diameter. The stream of NPs and gas atoms after exiting though the aperture, expanded into 
a cone (divergent beam) due to the pressure differential between the aggregation zone and the main chamber. In line with the NP source, a quadrupole mass spectrometer (MesoQ, Mantis Deposition Ltd., Thame, UK) was used to detect the mass distribution of the formed NPs and act as a filter with accuracy $0.2 \%$ in size. This hybrid deposition system was presented into more detail in a previous publication [21].

For this study, a varying methane to argon gas mixture ratio of 3:1, 2:1 and 1:1 was introduced into the quartz discharge chamber of the ion beam while the RF power was kept at $200 \mathrm{~W}$ and the inner grid voltage was set to $100 \mathrm{~V}$. The working pressure of the chamber was between 0.02 and $0.05 \mathrm{~Pa}$ during all depositions and substrates were kept at ground potential, while the deposition time for all samples was $30 \mathrm{~min}$. Silver and copper sputtering targets of 4 and $5 \mathrm{~N}$ purity, respectively, were used for the fabrication of NPs and Ar (purity $5 \mathrm{~N}$ ) was used as the sputtering gas. The discharge current and voltages were $30 \mathrm{~mA}$ and $250 \mathrm{~V}$ and $65 \mathrm{~mA}$ and $260 \mathrm{~V}$ for the Ag and $\mathrm{Cu}$ targets, respectively.

The optical response of the films were measured by a UV/Vis spectrometer in reflectance mode. The complex refractive index coefficients $(n, k)$ were extracted by fitting the experimental reflectivity measurements with an air/HDLC/Si three layer model in combination with a classical Lorentz oscillator dispersion relation. Fitting to the experimental data was performed using the RefFIT software (v1.3) [31].

$X$-ray reflectivity (XRR) and grazing incidence X-ray diffraction (GIXRD) measurements were performed in a diffractometer (Rigaku Ultima IV, Tokyo, Japan), equipped with a Cu tube operated in $40 \mathrm{kV}$ and $40 \mathrm{~mA}$. The X-ray beam was shaped by a curved multilayer mirror in parallel mode (Rigaku CBO optic, Tokyo, Japan) and by divergent and receiving slits without knife edge. The experimental XRR data were fitted using GlobalFit software (v2.0.4) from Rigaku.

The topographic characteristics for all films were collected with a Scanning Probe Microscope (Ntegra Prima, NT-MDT, Moscow, Russia) using intermittent contact mode atomic force microscopy (IC-AFM) with controlled humidity $(\sim 30 \%)$ and room temperature conditions. Images of $3 \mu \mathrm{m} \times 3 \mu \mathrm{m}$ were collected by oscillating a flexible cantilever with a sharp probe (NSG10) upon the surface of the materials while keeping the scanning rate at $1 \mathrm{~Hz}$. The qualitative and quantitative characteristics of the images were evaluated using the open software package, Gwyddion [32].

\section{Results and Discussion}

\subsection{Pure HDLC Films}

As a starting point in the effort to deposit HDLC:metal nanocomposites, pure hydrogenated amorphous carbon films, without any metal NPs, were grown. Three samples were deposited using $\mathrm{CH}_{4}$ to Ar ratio values $\left(\mathrm{CH}_{4} / \mathrm{Ar}\right)$ of 3:1, 2:1 and 1:1. We had chosen to vary the gas mixture as a mean to control the deposition rate of the thin films instead of RF power in consideration of the particular characteristics of the ion beam source. The normalized XRR patterns of the pure HDLC samples are shown in Figure 1a, with an offset in the vertical axis intentionally introduced for clarity.

All reflectivity curves have similar patterns and show fringes up to $5^{\circ}$ angle which indicate high quality and smooth thin films. The critical angle of the curves, indicated with a vertical dashed line in Figure 1a, which relates to the mass density of the films, remains unaffected by the gas ratio used implying that the density of the films is approximately the same in all deposited films. The experimental reflectivity data were fitted in a three-layer model (film/SiC/Si) using GlobalFit software, and the density was found to be $2.0 \mathrm{~g} / \mathrm{cm}^{3}$ for all films independently of the gas ratio used. The thicknesses of the films were found to be 40,38 and $20 \mathrm{~nm}$ for the 3:1, 2:1 and 1:1 $\mathrm{CH}_{4} /$ Ar ratio respectively. The amplitude changes of the reflectivity curves in the angular range between $1^{\circ}$ and $2^{\circ} 2 \theta$ are attributed to the formation of an intermediate layer between the silicon substrate and the amorphous hydrogenated carbon film due to the high kinetic energy of impacting species which is above the sub-plantation threshold [33-35]. The roughness of the thin films was obtained from the fitting process and was found to be between 0.3 and $0.5 \mathrm{~nm}$ for all samples. 


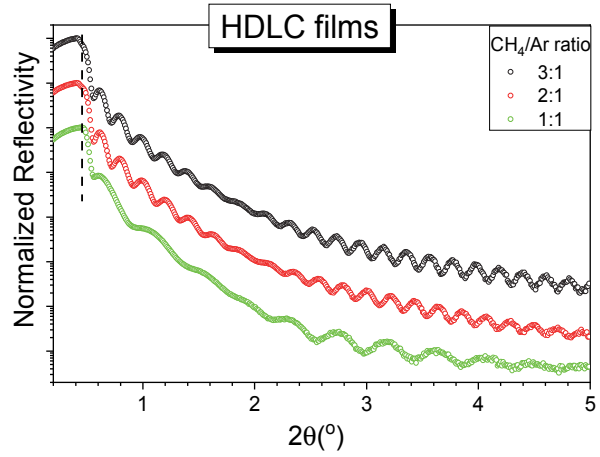

(a)

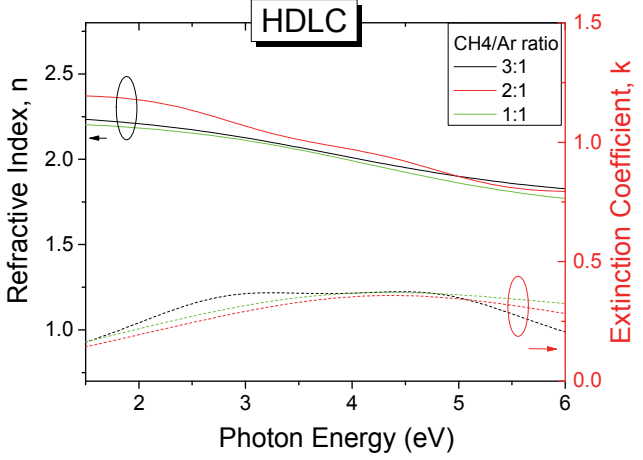

(b)

Figure 1. (a) Normalized X-ray reflectivity (XRR) patterns (with vertical shift for clarity) and (b) optical constants $\mathrm{n}, \mathrm{k}$ for pure hydrogenated diamond-like carbon (HDLC) thin films deposited with different $\mathrm{CH}_{4} /$ Ar gas ratio.

The specular reflectance in the UV/Vis range of the deposited HDLC samples was measured and by appropriate fitting of the experimental curves using a two-layer model (film on $\mathrm{Si}$ ) the optical constants of the film were obtained. Figure $1 b$ shows the extracted $n$ and $k$ values for the three HDLC films grown with different gas ratios. All samples show similar behavior in this spectral range, further supporting the XRR results. The values of $n$ range from 2.25 to 1.90 for the low and high energy photons respectively and the maximum value of $\mathrm{k}$ does not exceed 0.4. These values are in good agreement with similar samples grown using an ion beam [36]. The optical properties of hydrogenated amorphous carbon are governed by their bonding characteristics and the hybridization of the carbon atoms, and specifically the $\mathrm{sp}^{3} / \mathrm{sp}^{2}$ ratio and the composition of hydrogen. The $\mathrm{sp}^{3}$ fraction of our samples was estimated in a previous work [21] by Raman spectroscopy and it was in the order of $50 \%$, while the hydrogen content was $20 \%-25 \%$. The above results place the samples under the category of HDLC films.

\subsection{HDLC with Metal NPs}

The HDLC samples containing metal NPs were fabricated by co-deposition of carbon through the ion beam source and metallic clusters through the NP source. The experimental parameters for the ion beam were kept the same as the pure HDLC films while the NP source was configured to provide the maximum flux of NPs with the widest diameter range. The main deposition parameters that affect the diameter range of the NPs are (apart from the material) the length of the aggregation zone, the sputtering power and the gas flow. The configuration of the source was performed by monitoring the inline mass spectrometer (MesoQ filter) and by changing the aforementioned parameters we established the desired NP distribution. Figure 2a shows the normalized current intensity of the produced NPs versus the NP diameter for Ag (black circles) and $\mathrm{Cu}$ (red circles). The diameter of the NPs ranges between 1 and $15 \mathrm{~nm}$ for both materials, while the center of the peaks is between 7 and $8 \mathrm{~nm}$. The inline filter allows for pre-selecting a single size diameter NPs with an accuracy of $\pm 2 \%$ but in this study during deposition we allowed the full size spectrum of generated NPs to pass through, in order to achieve a higher deposition rate on the sample surface.

Figure $2 \mathrm{~b}$ shows a $3 \mu \mathrm{m} \times 3 \mu \mathrm{m}$ AFM image of pure Ag NPs deposited on Si wafer for $30 \mathrm{~min}$. The NPs are distributed randomly and homogenously on the surface and the coverage is high but not complete. The brighter spots are pile-ups of two or three NPs considering their diameter distribution from the graphs of Figure 2a and their shape appears round as expected from the gas phase nucleation and growth which promotes spherical shapes. In a previous work we verified that the size detected by the inline filter matches very well with the actual size of the NPs by a combined AFM and High-Resolution Transmission Electron Microscope (HRTEM) characterization [21]. One question 
that we expect to resolve in this study is how these NPs would interact with the high kinetic energy carbon/argon atoms arriving from the ion beam source.

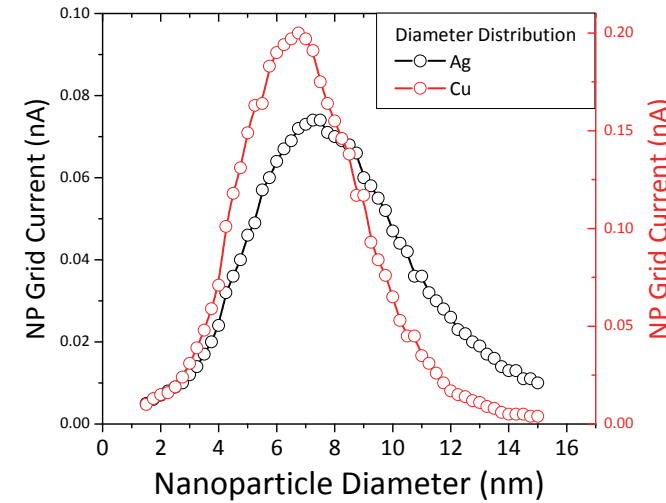

(a)

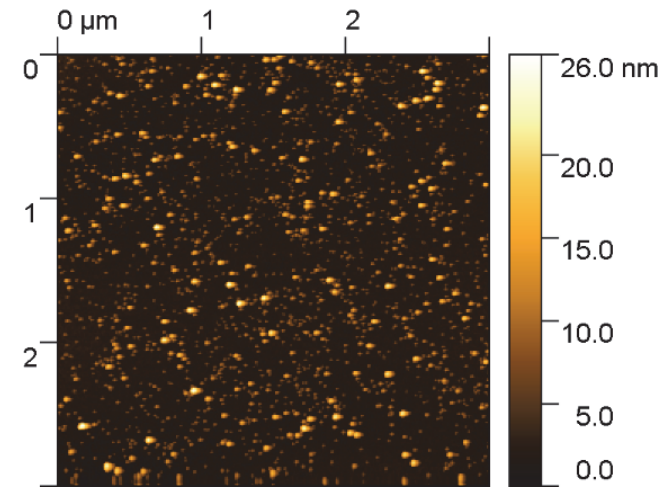

(b)

Figure 2. (a) Grid current intensity versus nanoparticle (NP) diameter for silver (black circles) and copper NPs (red circles). (b) Atomic force microscopy (AFM) image of pure Ag NPs on Si wafer.

It is known that the filling factor/metal content of the nanocomposites with metal inclusions plays a significant role in the final properties of the films [18]. In this study, we have changed the $\mathrm{CH}_{4} / \mathrm{Ar}$ ratio in order to vary the deposition rate of the carbon matrix while keeping the metal NP flux constant. Figure 3a shows the XRR experimental curves of HDLC thin films containing Ag (top group) and $\mathrm{Cu}$ (bottom group). The experimental curves were fitted to a three-layer model (film/interface layer/substrate) and a representative calculation is shown with a magenta line overlaying the corresponding experimental curve in Figure 3a. From the fitting, the density of the samples is found to be $2 \mathrm{~g} / \mathrm{cm}^{3}$ for all samples, independently from the containing metal. The incorporation of the metal nanoclusters did not alter the measured density of the films which might be explained by either the low metal content and the low graphitization of the films $[18,29]$. The thicknesses of the samples were 28 to $16 \mathrm{~nm}$ for the AgNPs nanocomposites and 49 to $28 \mathrm{~nm}$ of the Cu-NPs nanocomposites. From the shape of the curves one can see that no layering has been detected in the bulk of the thin films which implies a homogeneous distribution of the metallic NPs along the growth direction. The root mean square roughness of all samples with $\mathrm{Ag}$ and $\mathrm{Cu}$, as estimated through XRR measurements, was between 0.4 and $0.6 \mathrm{~nm}$. Figure $3 \mathrm{~b}$ shows the GIXRD patterns of pure NP film (red) and HDLC nanocomposites of varying $\mathrm{CH}_{4} / \mathrm{Ar}$ ratio. Only the sample with freestanding Ag NPs exhibits a clear Ag [111] peak and a weak [200] peak. The [111] peak also appears symmetric and very close to the angular position of a bulk sample (noted with vertical dashed lines), implying a soft-landing regime and a stress-free lattice constant. The nanocomposite samples do not exhibit any diffraction peaks, suggesting a rather small number of NPs per unit area and thus a low metal concentration.

Figure 4 shows a grid of AFM scans of the composite thin film samples grown with different $\mathrm{CH}_{4} / \mathrm{Ar}$ ratio and the same NP flux as well as size distribution, as shown in Figure 2a. Clearly, for all samples the metal NPs are observed in the scans without any signs of aggregation or coalescence, however their surface coverage compared to the sample without HDLC decreased. The root mean square roughness $\left(R_{\mathrm{q}}\right)$ lies within the range of 0.2 and $0.8 \mathrm{~nm}$ for all samples, while the average roughness $\left(R_{\mathrm{a}}\right)$ exhibits lower values in the range between 0.08 and $0.27 \mathrm{~nm}$. Both definitions of roughness reside in the sub-nanometer regime and relate primarily to the surface characteristics of the amorphous carbon matrix deposited within this study. The contribution of the metallic NPs plays an insignificant role due to the very low concentrations. Additionally, the root mean square values of roughness obtained through AFM $(0.2-0.8 \mathrm{~nm})$ are in close agreement with the values obtained through XRR analyses $(0.3-0.6 \mathrm{~nm})$. The roughness definition more heavily affected by the presence of NPs is the peak to valley height $\left(R_{\mathrm{z}}\right)$ which shifts in the tenths of nanometers regime (13.7 to $16.7 \mathrm{~nm}$ 
for HDLC:Ag and 17.3 to $17.7 \mathrm{~nm}$ for HDLC:Cu) consistent with the size of NPs grown within this study and unaffected by their quantity or content. It is interesting to note that the type of metal or the $\mathrm{CH}_{4} /$ Ar ratio does not influence $R_{\mathrm{z}}$ which is consistent with the fact that the size of the NPs is independently controlled through the deposition setup/mass filter.

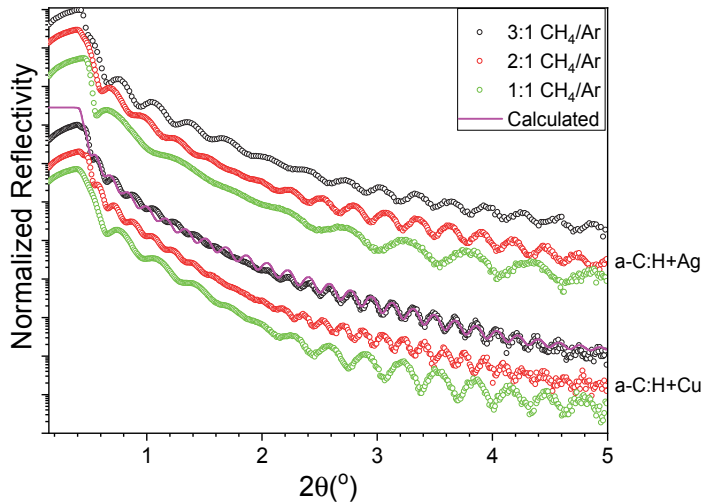

(a)

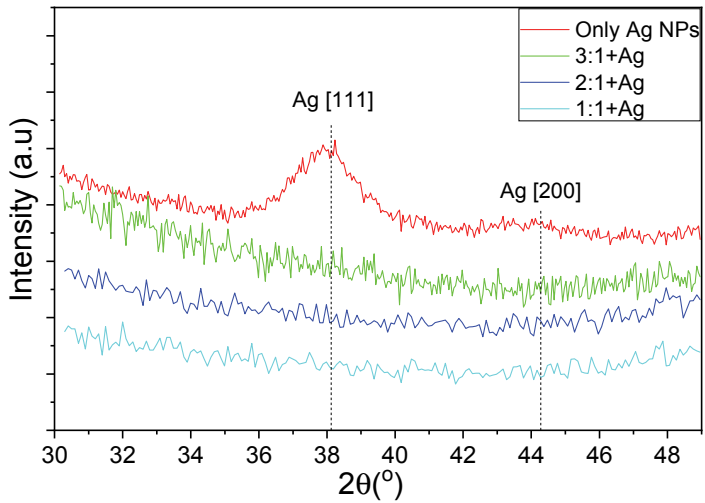

(b)

Figure 3. (a) XRR curves for HDLC containing Ag (top group) and $\mathrm{Cu}$ (bottom group) and (b) grazing incidence X-ray diffraction (GIXRD) patterns of pure NP film (red) and HDLC nanocomposites of varying $\mathrm{CH}_{4} /$ Ar ratio.

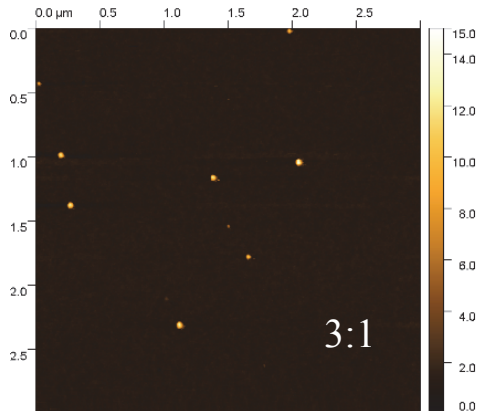

(a)

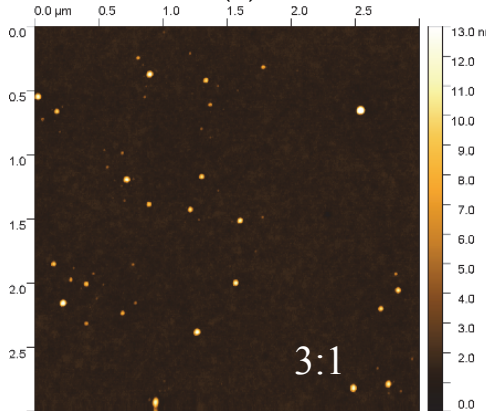

(d)

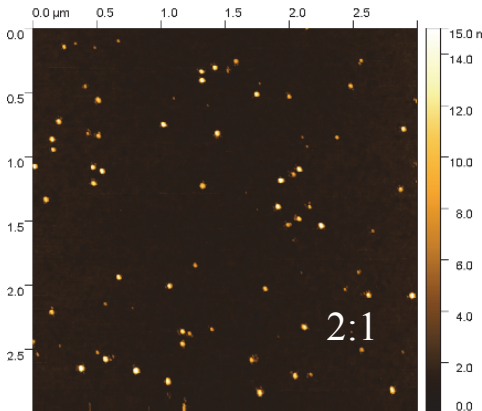

(b)

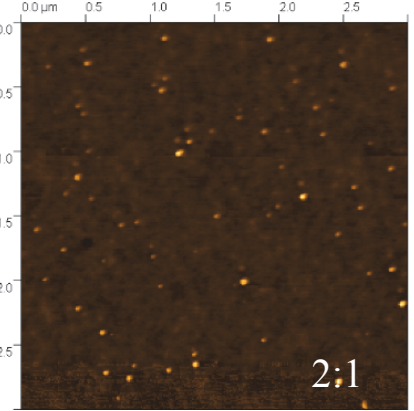

(e)

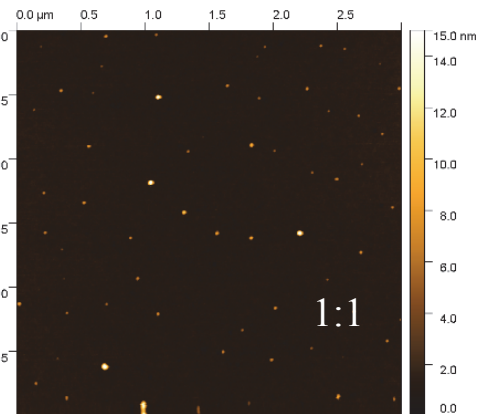

(c)

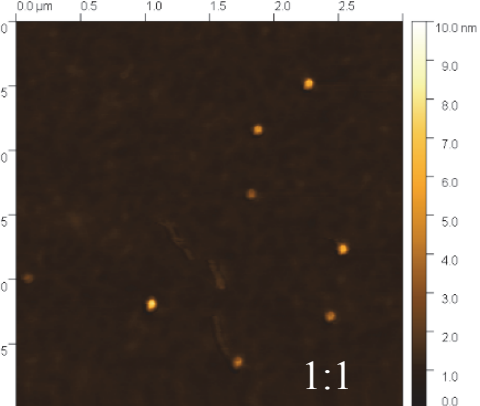

(f)

Figure 4. (a) AFM $3 \mu \mathrm{m} \times 3 \mu \mathrm{m}$ scans for HDLC/Ag (a-c) and (b) HDLC/Cu (d-f) samples grown at various $\mathrm{CH}_{4} /$ Ar ratios (3:1, 2:1 and 1:1).

The reduction in the number of NPs can be explained by the energetic conditions during ion beam deposition of HDLC. The incoming carbon/argon ions are partially re-sputtering NPs already deposited at the sample surface, creating in some cases surface voids that are subsequently filled with amorphous carbon. This explanation can be strengthened by the sporadic craters appearing in the flat background, mostly for the $\mathrm{Cu}$-containing samples. For this reason, to deposit nanocomposites 
with higher NP concentration, the re-sputtering should be taken into consideration and the deposition process should be adapted accordingly. This can be circumvented either by increasing the deposition flux of the NPs to compensate for their losses or by using an alternative approach such as a sequential deposition of the matrix and the NPs.

Assessing the observed reduction in the number of NPs per unit area from the AFM scans (Figure 4) it appears that the metal loading is rather low, estimated in the order of sub 1\%. Even at this low metal content, the properties of the nanocomposite differ from the properties of the pure matrix. Low metal NP content has been found to enhance the nanoscratch resistance and partially relieve the residual stress [21] of the matrix and induce antimicrobial properties [37]. In similar nanocomposite systems and also as shown by ab initio calculations, a reduction in the $\mathrm{sp}^{3}$ content was observed $[18,29]$ due to graphitization of the HDLC matrix around the NPs. The graphitization of the matrix should increase the optical absorbance of the films, which might or might not be desirable, depending on the application. For photonic and plasmonic applications a reduction in the transparency of the matrix is not desirable and needs to be avoided.

The transmittance and extinction spectra of the pure Ag NPs sample deposited on quartz are shown in Figure 5a. A distinct absorption peak is observed at $3.16 \mathrm{eV}$, which is due to LSPR of the metallic Ag NPs. The absorption value is well correlated with the LSPR absorption shown by similar sizes of Ag NPs [38]. This resonance originates from the collective oscillation of the free electrons of the NPs, and affected by the size of the NPs, the distance between them and the optical properties of the surround matrix [39]. The top of Figure 5b shows the measured experimental reflectivity of the HDLC; HDLC:Ag and HDLC:Cu thin films for 2:1 $\mathrm{CH}_{4} / \mathrm{Ar}$ ratio and their corresponding fit lines for each curve. All curves show a drop in the spectra between 3 and $4.5 \mathrm{eV}$, which is due to the evolution of a reflectivity fringe due to the transparency and the thickness of each sample; thicker samples would exhibit multiple reflectivity fringes in this range. The overlaid lines demonstrate the calculated reflectivities and all three curves show very good agreement to the experimental data.

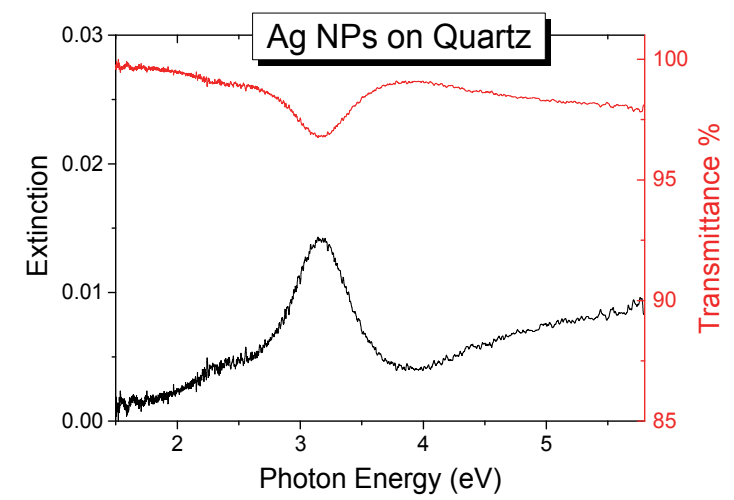

(a)

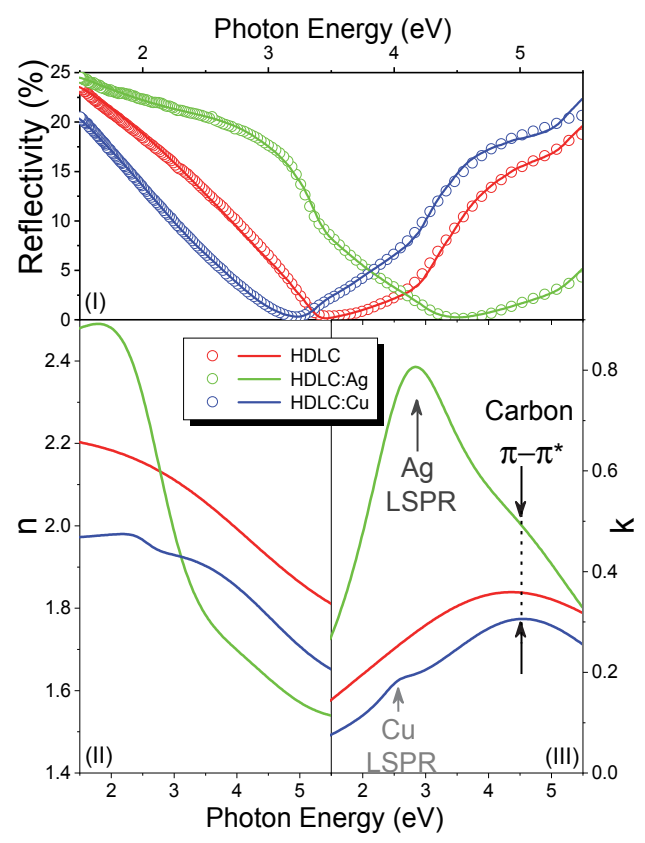

(b)

Figure 5. (a) Extinction (left, black) and transmittance (right, red) spectra of pure Ag NPs deposited on quartz. (b)(top) Normalized reflectivity (open circles) and their corresponding fit curves; the extracted (bottom left) $\mathrm{n}$ and (bottom right) $\mathrm{k}$ values of the pure HDLC (black), HDLC:Ag (green) and HDLC:Cu (blue) nanocomposites. 
The bottom part of Figure $5 b$ shows the extracted $n$ (left) and $k$ (right) values of the thin films as obtained from the fitting process. The values of $n$ and $k$ for the HDLC and HDLC:Cu samples are close to each other indicating similar optical behavior before and after the metal doping. The values of $\mathrm{n}$ are in the range between 1.65 and $2.2 \mathrm{eV}$ for the high and low energy part of the spectrum. The highest value of the extinction coefficient $\mathrm{k}$, in the measured range is located around $4.5 \mathrm{eV}$, which is very similar to the pure HDLC value. Additionally, a faint peak was observed at $2.6 \mathrm{eV}$ which is assigned to the LSPR of $\mathrm{Cu}$ NPs. The refractive index of nanocomposites with Ag (Figure 5b, bottom left) has even larger value span from 1.45 to 2.45 in comparison to pure HDLC. The addition of Ag NPs resulted in higher absorption and a broad peak in the spectrum, around $2.7 \mathrm{eV}$. The same peak is also observed in the 3:1 $\mathrm{CH}_{4} /$ Ar ratio grown sample but not in the 1:1, possibly due to low film thickness and the poor fitting convergence of the latter. This peak is assigned to the LSPR of Ag as [14,40,41], which is more pronounced in comparison with HDLC:Cu as expected.

The manifestation of both LSPR peaks for Ag and $\mathrm{Cu}$ NPs indicates that the HDLC matrix retains its transparency after the metal addition, as also shown by the comparison between the pure HDLC. Table 1 shows the position of the $\pi-\pi^{*}$ transition of the matrix and the LSPR as extracted from the fitting process. The spectral position of the $\pi-\pi^{*}$ transition is coupled with the bonding characteristics of the carbon matrix and it shifts to lower energies for smaller $\mathrm{sp}^{3} / \mathrm{sp}^{2}$ ratio. By comparing the values of Table 1, we observe a reduction in the energy of the $\pi-\pi^{*}$ transition from 5.08 to 4.65 and $4.85 \mathrm{eV}$ for $\mathrm{Ag}$ and $\mathrm{Cu}$ respectively. This redshift indicates a graphitization of the matrix which on the other hand is reduced, compared with other metal containing carbon nanocomposites [42]. The values of the second oscillator are indicating the position of the LSPR absorption which are also in accordance with similar nanocomposite system $[43,44]$.

Table 1. Oscillator positions for pure and metal containing HDLC.

\begin{tabular}{ccc}
\hline Sample & Oscillator Position for $\pi-\pi^{*}(\mathbf{e V})$ & Oscillator Position for LSPR $(\mathbf{e V})$ \\
\hline HDLC & 5.08 & - \\
HDLC:Ag & 4.65 & 2.75 \\
HDLC:Cu & 4.85 & 2.57 \\
\hline
\end{tabular}

\section{Conclusions}

We have demonstrated the successful deposition of pure HDLC, pure metal NPs and HDLC:metal nanocomposites with embedded Ag and $\mathrm{Cu}$ NPs through the utilization of a novel CVD/PVD hybrid deposition system in which the formation of NPs is decoupled from the HDLC matrix deposition via the novel deposition system design. The pure HDLC samples exhibit transparency and the values of refractive index were between 2.25 to 1.90 for the low and high energy photons respectively. The density was found to be $2.0 \mathrm{~g} / \mathrm{cm}^{3}$ and the surface roughness was in the sub-nanometer scale. AFM scans show that the nanocomposite HDLC thin films contained spherical, non-agglomerated NPs of Ag or $\mathrm{Cu}$, with controlled size distribution between 1 and $15 \mathrm{~nm}$, verifying the output of the quadrupole mass spectrometer located in line with the cluster beam source. A reduction in the number of NPs was noted between pure NPs films and HDLC:metal nanocomposites due to the resputtering of surface and poorly attached NPs by the ion beam during the co-deposition. The UV/Vis measurements demonstrated that the addition of metal NPs, especially for $\mathrm{Cu}$ in the HDLC films resulted in retaining the optical transparency and response of the nanocomposite HDLC films, at the same level as the pure HDLC. This was achieved by reducing the interactions of the metal and the matrix and keeping the graphitization of the amorphous carbon matrix network low. The nanocomposite thin films with Ag NPs exhibit a similar level of absorbance with the pure HDLC films, with an additional broad peak located at $2.7 \mathrm{eV}$ which is assigned to the manifestation of the LSPR of Ag NPs. The average roughness of the nanocomposite thin films for both metals was low, again in the sub-nanometer scale. These results demonstrate that the decoupling of the NPs formation from the HDLC matrix can reduce 
the graphitization of the matrix, enabling the development of such types of nanocomposite that can be exploited in various applications ranging from protective coatings to photonic devices.

Author Contributions: Conceptualization, L.K., G.C. and P.K.; Formal analysis, L.K., M.C. and G.C.; Investigation, L.K., M.C. and P.N.; Methodology, L.K.; Writing—original draft, L.K. and G.C.; Writing-review \& editing, L.K., G.C. and P.K. All authors have read and agreed to the published version of the manuscript.

Funding: The authors would like to acknowledge the financial support from the Strategic Infrastructure Project NEW INFRASTRUCTURE/STRATE/0308/04 of DESMI 2008, which is co-financed by the European Regional Development Fund, the European Social Fund, the Cohesion Fund, and the Research Promotion Foundation of the Republic of Cyprus. The continued support from Cyprus University of Technology towards RUNMS is gratefully acknowledged. LK, MC, and GC would also like to acknowledge the M-ERA.NET and the Cyprus Research Promotion Foundation (RPF) for the support they receive under the project P2P/M-ERA.NET/0317/0008 (BElectroCathode).

Conflicts of Interest: The authors declare no conflict of interest. The funding sponsors had no role in the design of the study; in the collection, analyses, or interpretation of data; in the writing of the manuscript, and in the decision to publish the results.

\section{References}

1. Robertson, J. Diamond-like amorphous carbon. Mater. Sci. Eng. R Rep. 2002, 37, 129-281. [CrossRef]

2. Weiler, M.; Sattel, S.; Giessen, T.; Jung, K.; Ehrhardt, H.; Veerasamy, V.S.; Robertson, J. Preparation and properties of highly tetrahedral hydrogenated amorphous carbon. Phys. Rev. B 1996, 53, 1594-1608. [CrossRef] [PubMed]

3. Rodil, S.E.; Olivares, R.; Arzate, H.; Muhl, S. Properties of carbon films and their biocompatibility using in-vitro tests. Diam. Relat. Mater. 2003, 12, 931-937. [CrossRef]

4. Piazza, F.; Grambole, D.; Schneider, D.; Casiraghi, C.; Ferrari, A.; Robertson, J. Protective diamond-like carbon coatings for future optical storage disks. Diam. Relat. Mater. 2005, 14, 994-999. [CrossRef]

5. Cloutier, M.; Harnagea, C.; Hale, P.; Seddiki, O.; Rosei, F.; Mantovani, D. Long-term stability of hydrogenated DLC coatings: Effects of aging on the structural, chemical and mechanical properties. Diam. Relat. Mater. 2014, 48, 65-72. [CrossRef]

6. Fontaine, J.; Le Mogne, T.; Loubet, J.; Belin, M. Achieving superlow friction with hydrogenated amorphous carbon: Some key requirements. Thin Solid Films 2005, 482, 99-108. [CrossRef]

7. Robertson, J. Comparison of diamond-like carbon to diamond for applications. Phys. Status Solidi 2008, 205, 2233-2244. [CrossRef]

8. Grigonis, A.; Šablinskas, V.; Šilinskas, M.; Tribandis, D. The role of hydrogen in a-C:H films deposited from hexane or acetylene using direct ion beam deposition method. Vacuum 2004, 75, 261-267. [CrossRef]

9. Silinskas, M.; Grigonis, A.; Kulikauskas, V.; Manika, I. Hydrogen influence on the structure and properties of amorphous hydrogenated carbon films deposited by direct ion beam. Thin Solid Films 2008, 516, 1683-1692. [CrossRef]

10. Panagiotopoulos, N.; Karras, G.; Lidorikis, E.; Koutsogeorgis, D.; Kosmidis, C.; Patsalas, P. Photosensitivity and optical performance of hydrogenated amorphous carbon films processed by picosecond laser beams. Surf. Coatings Technol. 2011, 206, 734-741. [CrossRef]

11. Patsalas, P. Optical properties of amorphous carbons and their applications and perspectives in photonics. Thin Solid Films 2011, 519, 3990-3996. [CrossRef]

12. Kuramoto, K.; Domoto, Y.; Hirano, H.; Kiyama, S.; Tsuda, S. High quality diamond like carbon thin film fabricated by ECR plasma CVD. Appl. Surf. Sci. 1997, 113, 227-230. [CrossRef]

13. Tachimoto, Y.; Noborisaka, M.; Shirakura, A.; Kuroyanagi, C.; Suzuki, T. Gas Barrier Properties of Diamond-like Carbon Films Synthesized by Using Remote Type Microwave Plasma CVD under Sub-ambient Atmospheric Pressure. J. Phys. Conf. Ser. 2013, 417, 012043. [CrossRef]

14. Tamulevičius, S.; Meškinis, Š.; Tamulevičius, T.; Rubahn, H.-G. Diamond like carbon nanocomposites with embedded metallic nanoparticles. Rep. Prog. Phys. 2018, 81, 024501. [CrossRef] [PubMed]

15. Aijaz, A.; Louring, S.; Lundin, D.; Kubart, T.; Sarakinos, K.; Helmersson, U.; Jensen, J. Synthesis of hydrogenated diamondlike carbon thin films using neon-acetylene based high power impulse magnetron sputtering discharges. J. Vac. Sci. Technol. A 2016, 34, 61504. [CrossRef] 
16. Popescu, A.C.; Stan, G.; Duta, L.M.; Nita, C.; Popescu, C.; Surdu, V.A.; Husanu, M.A.; Bita, B.; Ghisleni, R.; Himcinschi, C.; et al. The Role of Ambient Gas and Pressure on the Structuring of Hard Diamond-Like Carbon Films Synthesized by Pulsed Laser Deposition. Materials 2015, 8, 3284-3305. [CrossRef]

17. Panagiotopoulos, N.T.; Diamanti, E.K.; Koutsokeras, L.; Baikousi, M.; Kordatos, E.; Matikas, T.E.; Gournis, D.; Patsalas, P. Nanocomposite Catalysts Producing Durable, Super-Black Carbon Nanotube Systems: Applications in Solar Thermal Harvesting. ACS Nano 2012, 6, 10475-10485. [CrossRef]

18. Zoubos, H.; Koutsokeras, L.; Anagnostopoulos, D.; Lidorikis, E.; Kalogirou, S.; Wildes, A.; Kelires, P.; Patsalas, P. Broadband optical absorption of amorphous carbon/Ag nanocomposite films and its potential for solar harvesting applications. Sol. Energy Mater. Sol. Cells 2013, 117, 350-356. [CrossRef]

19. Bellas, D.V.; Lidorikis, E. Design of high-temperature solar-selective coatings for application in solar collectors. Sol. Energy Mater. Sol. Cells 2017, 170, 102-113. [CrossRef]

20. Constantinou, M.; Pervolaraki, M.; Koutsokeras, L.; Prouskas, C.; Patsalas, P.; Kelires, P.; Giapintzakis, J.; Constantinides, G. Enhancing the nanoscratch resistance of pulsed laser deposited DLC films through molybdenum-doping. Surf. Coatings Technol. 2017, 330, 185-195. [CrossRef]

21. Constantinou, M.; Nikolaou, P.; Koutsokeras, L.; Avgeropoulos, A.; Moschovas, D.; Varotsis, C.; Patsalas, P.; Kelires, P.C.; Constantinides, G. Metal (Ag/Ti)-Containing Hydrogenated Amorphous Carbon Nanocomposite Films with Enhanced Nanoscratch Resistance: Hybrid PECVD/PVD System and Microstructural Characteristics. Nanomaterials 2018, 8, 209. [CrossRef] [PubMed]

22. Liu, Y.; Chen, L.; Zhang, B.; Cao, Z.; Shi, P.; Peng, Y.; Zhou, N.; Zhang, J.; Qian, L. Key Role of Transfer Layer in Load Dependence of Friction on Hydrogenated Diamond-Like Carbon Films in Humid Air and Vacuum. Materials 2019, 12, 1550. [CrossRef] [PubMed]

23. Miyake, S.; Suzuki, S.; Miyake, M. Friction Durability of Extremely Thin Diamond-Like Carbon Films at High Temperature. Materials 2017, 10, 159. [CrossRef] [PubMed]

24. Yaremchuk, I.; Meškinis, Š.; Bulavinets, T.; Vasiliauskas, A.; Andrulevičius, M.; Fitio, V.; Bobitski, Y.; Tamulevičius, S. Effect of oxidation of copper nanoparticles on absorption spectra of DLC:Cu nanocomposites. Diam. Relat. Mater. 2019, 99, 107538. [CrossRef]

25. Shen, Y.; Qi, T.; Qiao, Y.; Hei, H.; He, Z.; Yu, S.; Yu, Q. Optical, electrical and microstructural properties of nanocomposite Ag/diamond by Ag ion implantation and subsequent annealing. Vacuum 2016, 123, 160-166. [CrossRef]

26. Meškinis, S.; Čiegis, A.; Vasiliauskas, A.; Tamulevičiene, A.; Šlapikas, K.; Juškenas, R.; Niaura, G.; Tamulevičius, S. Plasmonic properties of silver nanoparticles embedded in diamond like carbon films: Influence of structure and composition. Appl. Surf. Sci. 2014, 317, 1041-1046. [CrossRef]

27. Peckus, D.; Tamulevičius, T.; Meškinis, Š.; Tamulevičienè, A.; Vasiliauskas, A.; Ulčinas, O.; Gulbinas, V.; Tamulevičius, S. Linear and nonlinear absorption properties of diamond-like carbon doped with $\mathrm{Cu}$ nanoparticles. Plasmonics 2017, 12, 47-58. [CrossRef]

28. Ghosh, B.; Guzmán-Olivos, F.; Espinoza-González, R. Plasmon-enhanced optical absorption with graded bandgap in diamond-like carbon (DLC) films. J. Mater. Sci. 2017, 52, 218-228. [CrossRef]

29. Tritsaris, G.A.; Mathioudakis, C.; Kelires, P.C.; Kaxiras, E. Optical and elastic properties of diamond-like carbon with metallic inclusions: A theoretical study. J. Appl. Phys. 2012, 112, 103503. [CrossRef]

30. Ahmed, S.F.; Moon, M.W.; Lee, K.R. Effect of silver doping on optical property of diamond like carbon films. Thin Solid Film. 2009, 517, 4035-4038. [CrossRef]

31. Kuzmenko, A.B. Kramers-Kronig constrained variational analysis of optical spectra. Rev. Sci. Instrum. 2005, 76, 1-9. [CrossRef]

32. Nečas, D.; Klapetek, P. Gwyddion: An open-source software for SPM data analysis. Cent. Eur. J. Phys. 2012, 10, 181-188. [CrossRef]

33. Patsalas, P.; Logothetidis, S.; Kelires, P.C.C. Surface and interface morphology and structure of amorphous carbon thin and multilayer films. Diam. Relat. Mater. 2005, 14, 1241-1254. [CrossRef]

34. Gioti, M.; Logothetidis, S. Interfacial stability and atomistic processes in the a-C/Si(100) heterostructure system. Phys. Rev. B - Condens. Matter Mater. Phys. 1999, 59, 5074-5081.

35. Hastas, N.A.; Dimitriadis, C.A.; Patsalas, P.; Panayiotatos, Y.; Tassis, D.H.; Logothetidis, S. Structural, electrical, and low-frequency-noise properties of amorphous-carbon-silicon heterojunctions. J. Appl. Phys. 2001, 89, 2832-2838. [CrossRef] 
36. Druz, B.; Zaritskiy, I.; Hoehn, J.; Polyakov, V.I.; Rukovishnikov, A.I.; Novotny, V. Direct ion beam deposition of hard (>30 GPa) diamond-like films from RF inductively coupled plasma source. Diam. Relat. Mater. 2001, 10, 931-936. [CrossRef]

37. Gorzelanny, C.; Kmeth, R.; Obermeier, A.; Bauer, A.T.; Halter, N.; Kümpel, K.; Schneider, M.F.; Wixforth, A.; Gollwitzer, H.; Burgkart, R.; et al. Silver nanoparticle-enriched diamond-like carbon implant modification as a mammalian cell compatible surface with antimicrobial properties. Sci. Rep. 2016, 6, 22849. [CrossRef]

38. Campos, A.; Troc, N.; Cottancin, E.; Pellarin, M.; Weissker, H.-C.; Lermé, J.; Kociak, M.; Hillenkamp, M. Plasmonic quantum size effects in silver nanoparticles are dominated by interfaces and local environments. Nat. Phys. 2018, 15, 275-280. [CrossRef]

39. Maier, S.A. Plasmonics: Fundamentals and Applications; Springer Science \& Business Media: Berlin, Germany, 2007.

40. Meškinis, Š.; Peckus, D.; Vasiliauskas, A.; Čiegis, A.; Gudaitis, R.; Tamulevičius, T.; Yaremchuk, I.; Tamulevičius, S. Photovoltaic Properties and Ultrafast Plasmon Relaxation Dynamics of Diamond-Like Carbon Nanocomposite Films with Embedded Ag Nanoparticles. Nanoscale Res. Lett. 2017, 12, 288. [CrossRef]

41. Li, S.; Bandy, J.; Hamers, R.J. Tunable coloration of diamond films by encapsulation of plasmonic Ag nanoparticles. Diam. Relat. Mater. 2018, 89, 190-196. [CrossRef]

42. Matenoglou, G.; Evangelakis, G.A.; Kosmidis, C.; Foulias, S.; Papadimitriou, D.; Patsalas, P. Pulsed laser deposition of amorphous carbon/silver nanocomposites. Appl. Surf. Sci. 2007, 253, 8155-8159. [CrossRef]

43. Jurkevičiūtè, A.; Lazauskas, A.; Tamulevičius, T.; Vasiliauskas, A.; Peckus, D.; Meškinis, Š.; Tamulevičius, S. Structure and density profile of diamond-like carbon films containing copper: Study by X-ray reflectivity, transmission electron microscopy, and spectroscopic ellipsometry. Thin Solid Film. 2017, 630, 48-58. [CrossRef]

44. Meškinis, S.; Čiegis, A.; Vasiliauskas, A.; Šlapikas, K.; Tamulevičius, T.; Tamulevičiene, A.; Tamulevičius, S. Optical properties of diamond like carbon films containing copper, grown by high power pulsed magnetron sputtering and direct current magnetron sputtering: Structure and composition effects. Thin Solid Film. 2015, 581, 48-53. [CrossRef]

(C) 2020 by the authors. Licensee MDPI, Basel, Switzerland. This article is an open access article distributed under the terms and conditions of the Creative Commons Attribution (CC BY) license (http://creativecommons.org/licenses/by/4.0/). 